\title{
COMPUTATIONAL SIMULATION AS AN ORGANIZATIONAL PROTOTYPING TOOL
}

\author{
Dosi, Clio; Iori, Manuel; Kramer, Arthur; Vignoli, Matteo \\ University of Modena and Reggio Emilia
}

\begin{abstract}
This case study deals with a redesign effort to face the overcrowding issue in an Emergency Department (ED). A multidiscinary group of healthcare professionals and engineers worked together to improve the actual processes. We integrate the simulation modeling in a human-centered design method. We use the simulation technique as a learning and experimentation tool into a design thinking process: the computational descrete event simulation helps explore the possibile scenarios to be prototyped. We used the simulation to create a virtual prototyping environment, to help the group start a safe ideation and prototyping effort. Virtual prototyping injected into the organizational context the possibility of experimenting. It represented a cognitive low-risk environment where professionals could explore possible alternative solutions. Upon those solutions, we developed organizational prototyping tools. Top management and head physicians gained confidence for a more grounded decision making effort and important choices of change management and investments have been made.
\end{abstract}

Keywords: Simulation, Decision making, Organizational processes

\section{Contact:}

Dosi, Clio

University of Modena and Reggio Emilia

DISMI Department of Science and Engineeering method

Italy

clio.dosi@unimore.it 


\section{INTRODUCTION}

In the last years, emergency departments (ED) attracted considerable attention of researchers mainly due to its practical and theoretical importance, complex structure and unpredictable nature. ED are characterized by being very flexible facilities able to admit patients with different levels of injuries/diseases and treatment requirements. ED overcrowding is a more and more urgent phenomenon (Trzeciak and Rivers, 2003), recognized as a relevant issue to be faced both from the medical community and the engineering community (Hoot and Aronsky, 2008).

Simulation modeling has been extensively used to improve health-care systems (see, e.g., Günal and Pidd 2010; Gul and Guneri 2015; Brailsford et al., 2017; Salmon et al., 2018). In the ED setting, the engineering community contributed to face the overcrowding issue by supporting the medical community with simulation studies, that applied scenarios to test results of organizational decision taken at different levels (Hulshof et al., 2012), from systemic level decisions (e.g. Brailsford et al., 2004), to organizational level decisions. In the last 40 years several studies have thus approached the ED overcrowding topic recurring to the simulation tool, although with different intentions, different simulation techniques and different approaches (e.g., Paul et al., 2010 for a review). Despite the significant and arising number of studies dealing with the ED overcrowding topic, and despite the fact that medical and managerial communities accept the important role of simulation studies, nowadays the simulation community recognize that there are still barriers to implement the results of the studies (see e.g., Fone et al., 2003). This approach to simulation is affirmed and replicated in the ED overcrowding studies: the engineer runs a sequence of what-if scenario dealing with different areas of interventions and the decision-maker considers the final result and how she could adapt it and implement it into the system upon which she can take decisions.

At the same time, the increasing interest in managing ED considering the needs of all the stakeholders involved leads to studies on health-care design. In this context, the focus on redesigning organizational processes in health-care, as a way to increase efficiency and patient satisfaction, is growing and new methods to measure the consequences of innovation on health services have been developed (Herzlinger 2006; Madsen et al., 2006; Prada 2008). To meet the real needs of health-care organizations, engineers and managers have focused their attention on organization design with the aim of reducing the gap between theory and practice (Romme 2003; Weick 2003; Mohrman 2007).

Recently, design thinking (Brown 2008; Martin 2010; Dosi et al., 2018) has taken on an important role among organizational design professionals, and the idea that designers can place human needs at the center of the innovation project. There are many cases in which design has been applied to health processes (e.g., Bate and Robert 2007; Bevan et al., 2007; Bessant and Maher 2009; Iedema et al., 2010; Starnino et al., 2016; Dosi et al., 2017) and it is an interesting opportunity to understand how, through design thinking, the collaboration between medicine, engineering and management can produce positive results for society. The design thinking process applied to the organizational processes is configured as a model of co-creation and involvement of all the stakeholders in the design (Cottam and Leadbeater 2004; Freire and Sangiorgi 2010). Designing (or re-designing) health-care processes from the patient's point of view is certainly a key concept in health sector improvement efforts. Innovation arises in the involvement of patients, doctors, nurses, process engineers and technologists in a shared process of innovation based on learning (Franchini et al., 2017) rather than applying best practices (Bate and Robert 2006; Jelinek et al., 2008). In this process, designers are asked to answer to the needs expressed by the all the actors involved in the change, and that is why the approach is defined as a human-centered design method. Designing around the users involved in the process reduces the risk related to innovation, and at the same time the chance of seeing the proposed solutions implemented increases (McCreary, 2010). In particular, the work team finds itself empathizing with the design challenge, and adapting its activities to the context factors that characterize the design process in question (Hempe et al., 2012).

In the presented case study, we integrate the simulation modeling in a human-centered design method. The case study deals with an ED overcrowding and we used the simulation technique as a learning and experimentation tool into a design thinking process. 


\section{INTEGRATING THE SIMULATION MODELING IN A HUMAN-CENTERED DESIGN METHOD}

\subsection{How design thinking hosts simulation modeling}

All Design Thinking projects have in common an iterative cycle of 4 exploration phases that is repeated throughout the project: (i) comprehension, (ii) abstraction, (iii) ideation and (iv) solution. In the comprehension phase, the team empathizes with the context, through the understanding of the design challenge and the organization in which it operates. At this stage, qualitative research tools, such as semistructured interviews and participatory observation, or quantitative research, such as questionnaires and data analysis can be used. In this phase, an in-depth analysis of the literature is also conducted aimed at acquiring relevant relations for the context, recurring problems and general solution ideas (Romme, 2003).

In the abstraction phase, the design team creates an abstract model of what is understood and defines the needs of the stakeholders. The main process modeling tools, such as BPMN - Business Process Model and Notation, system dynamics, agent based and discrete event modeling, are also used (Vignoli et al., 2011) and designing tools such as context map or needs map.

In the ideation phase, the team is aimed at generating, through brainstorming, bodystorming and other creative methods, the greatest number of possible solutions for the context in question. In this phase selected concept solutions are built in a prototype.

In the last phase we return to the field, to verify the emotional, cognitive and functional response of the organization to the prototypes made, and then restart the cycle.

Each phase is connected with the previous and the following phases, as the team members first assume a divergent exploratory attitude to generate a wide range of concepts and later converge into a smaller set of solutions, in an iterative way.

It is not necessary that the phases are carried out in the order presented. If the materials and ideas to build a prototype are already available, then one could, for example, move directly to the solution phase and vice-versa. Since in many cases the process starts from solutions already implemented, the team can decide to start from the solution phase by testing small variations to the existing solution to verify the effects of the changes on the organization.

In our work, we applied the four phases previously described aiming at improving patients and workers satisfaction. First, in the comprehension phase we collected key information by using different methods. Initially, a database containing historical data has been provided by the ED staff. In addition to that, key information such as patients flow through the ED and patient and ED staff needs has been collected by interviews and observation. Regarding this phase, the data collection and analysis performed are detailed in Section 3.1.

Then, in the second phase, the abstraction, the information obtained during the comprehension phase have been analyzed and integrated into a digital twin DES model with the objective of representing and understanding the ED operation under study as well as identifying the system weaknesses and improvement points to be tackled. Once the model built it should be validated (see Section 3.2). In our case, the validation has been done by the ED expert team. Then, after the model was validated it was possible to advance to the third phase of the design thinking process, the ideation. In the ideation phase, the previously proposed DES model has been used as a tool for proposing possible changes in the ED organization aiming at meeting the needs by tackling the weaknesses and improving points identified. Since the application and evaluation of changes in practice are very risky, a preliminary evaluation of the expected impact of the changes in practice have been done through the DES model. Hence, once the simulation model is built and validated, the use of this tool allows a fast and cheap what-if scenarios proposition and evaluation (see Sections 3.3 and 3.4). Indeed, this is one of the main advantages of using a digital twin simulation model.

Finally, after an extensive experimentation phase, a solution is selected to be implemented in practice and the impacts in the system are then evaluated and confronted with the expected results. This performance evaluation has the objective of evaluating the method effectiveness and is, usually, used as starting point of another design thinking cycle.

In general words, the design thinking process involves the problem comprehension and abstraction, and solution proposition and evaluation aiming at answering the needs by all the actors involved in the 
change. In particular, the problem abstraction and solution proposition phases implicate in the use of innovative and advanced methods. In this sense, activities such as semi-structured interviews, participatory observation, data collection and analysis, and the use of simulation modeling techniques can be used aiming at understanding, modeling and proposing improvement changes to the system.

\subsection{How simulation modeling is interpreted by designers}

The classical approach of simulation studies concentrate the multidisciplinary relationship around the simulation model itself, considering the implementation as a later stage and thus leaving the whole implementation issues to the decision makers. Differently, we used the simulation to create a digital twin, which is a virtual prototyping environment, to help the group start a safe ideation and prototyping effort (Liedtka, 2015). The concept of digital twins emerges in the industry 4.0 era and is characterized by being a virtual replica of a system responsible for modeling its data, functionality and communication interfaces (Schluse et al., 2018).

Virtual prototyping is the solution we used to project the design group into the state of possible, before involving them into an organizational prototyping activity. Virtual prototyping injected into the organizational context the possibility to experiment. It represented a (cognitive) low-risk environment where professionals could explore possible alternative solutions. It enabled the organization to take courage and identify possible paths that are worth investing energies to improve their performance. Top management and head physicians gained confidence for a more grounded decision making effort and important choices of change management and investments.

\section{CASE STUDY}

We investigate an ED located in the north of Italy which cover a region with approximately 1 million of inhabitants. The aforementioned ED admitted more than 62500 patients in the first 9 months of 2017. A discrete event simulation (DES) model is integrated with a design thinking process aiming at improving the ED key performance indicators (KPI) and at the same time to improve professionals' quality of work. We created an ad-hoc group with professionals of the ED department that were involved in the design process and decision making. The group met once every 10 days and the hospital top management were involved in the advancements once every 3 months. We approached the context with a design thinking process, sided with simulation-driven studies of the context. The DES model acts as a tool to help the understanding of the current system and to investigate possible changes in order to attain performance improvements.

\subsection{Patient flow and data analysis}

Before presenting our simulation model, we present some basic information required by it as input data. These are mainly the process flow under study and input data such as patient arrival rates, patient urgency distributions, resources availability, schedules, service times distribution and queue rules, among others. In order to retrieve these information, we applied two different techniques: (i) data collection and analysis, and (ii) observation. The former allows obtaining the required inputs by analyzing historical data, i.e., studying what happened in the past. The second approach usually is used when historical data is scarce or do not permits obtaining the main inputs needed. In our case, a consistent database containing data from January to September 2017 is available, but some information related to the service times cannot be obtained straight from this database.

Once the main flow was identified, the data requirement for setting-up the DES model emerges. Initially, basic information such as resource availability and personnel schedules have been make available by the ED staff. The queue rules currently used in the studied ED have been identified during the observation phase and by interviews performed with experts. In the one hand, quantitative information concerning the distributions about patients arrival rates, urgency and exams requirements have been directly retrieved from the database, as well as information about service times of additional exams such as laboratory and x-ray. On the other hand, information about some services execution times, which could not be directly obtained from the database, were obtained by in loco observation and by interviewing ED's staff. Figures $1 \mathrm{a}$ and $1 \mathrm{~b}$ illustrate the profiles of the urgency distribution and the arrival distribution per hour of the day, respectively. Then, a DES model is set-up with the objective of replicating the reality. Hence, the next step is the model validation. 


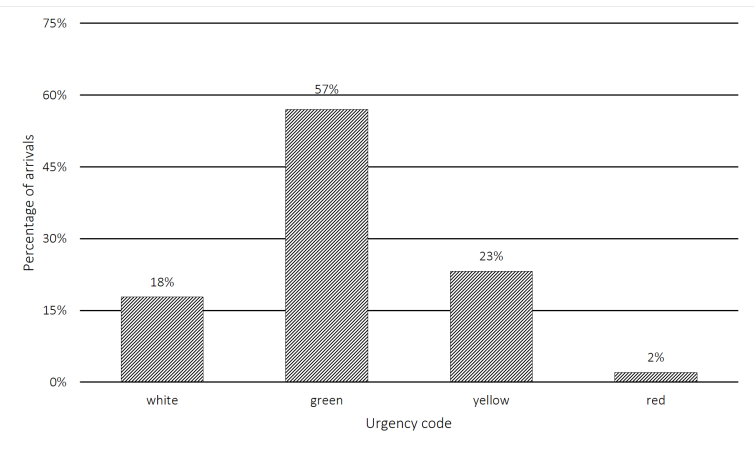

(a) Urgency distribution of arrivals



(b) Arrival distribution per hour of the day

Figure 1. Data analysis - patients' arrival and urgency distributions

\subsection{Model validation}

The validation phase is crucial before using a simulation model. This process is even more crucial when historical data is scarce. For more details about model validation we address the reader to the work of Robinson (1997). Our model validation phase is simplified because we used consistent data retrieved from the ED database. Our validation process is aligned with the one used by Aringhieri (2010). Before validating our model, we identified the KPI of interest that are correlated with the needs identified at the comprehension phase. Namely, the length of stay (LoS) and waiting time (WT) to first visit have been considered. LoS and WT are commonly used as KPI in the literature (see, e.g., Marshall et al., 2005; Santibáñez et al., 2009; Cabrera et al., 2011). Our reference values for the LoS and WT have been obtained directly from the available database and are shown in Figure 2.



(a) Average WT per urgency code



(b) Average WT per urgency and arrival time

Figure 2. Average waiting times for the first visit

In addition, we also consider outliers as a KPI. By outliers we mean the percentage of patients who wait more then a given threshold of time. This threshold depends on the patient's priority, based on their urgency, and on the ED internal, regional and national regulations. The reference thresholds were established as: 240 and 120 minutes for patients of white and green urgency codes, respectively.

Thus, the model has been validated by comparing the actual system indicators (measured based on the available historical data) with the results obtained by the proposed simulation model of the current ED setting. In the one hand, the historical results represents the average for the first 9 months of 2017. On the other hand, the simulation results were obtained by running the simulation model 10 times. Each run simulates 1 month of ED work. The obtained average results are presented in Table 1. Column In indicates the average number of patients arriving per day; columns $W T_{1 s t}$ and $L o S$ show the average waiting time for the first visit and the average length of stay (in minutes), respectively; finally, column Outliers (\%) show the percentage of patients, by priority, which exceeded the threshold time for waiting the first visit. 
Table 1. Model validation results

\begin{tabular}{lcccccc}
\hline Scenario & \multirow{2}{*}{ In } & $W T_{1 s t}$ & & LoS & \multicolumn{2}{c}{ Outliers (\%) } \\
\cline { 5 - 7 } & & & & green & white \\
\hline Past & 237.03 & 83.27 & 206.43 & 9.62 & 14.67 \\
Simulation & 238.23 & 70.52 & 208.60 & 3.88 & 25.47 \\
\hline
\end{tabular}

As can be seen in Table 1, the obtained values for $W T_{1 s t}$ and outliers are not as accurate as we would. This is mainly due to the lack of important quantitative data concerning the service times. Although this, the model has been validated by ED managers and staff involved in the work.

\subsection{Scenarios proposition}

This section presents a set of scenarios proposed aiming at improving the ED performance, measured based on KPI. The scenarios were proposed based on the needs and on the weaknesses and possible intervention points identified. In this sense, the following major problems have been identified: (i) many patients of white urgency code arriving to the ED actually do not need any emergency service; (ii) the transport of blood samples required by the laboratory exams is very inefficient and usually requires a large amount of time; (iii) and to most of the patients laboratory exams are required, but only during the first visit in the current setting.

Concerning the first point, the mentioned patients stay in the waiting room until the first visit. Usually, after this visit they are dismissed without requiring any extra examinations. Since their priorities are low these their waiting times tend to be high, thus impacting to the increasing in the average waiting times and in the number of outliers. Regarding to the second and third points, most of the additional exams require the results of laboratory exams to be performed. Therefore, if they are required only after the first visit and if the transportation time is high, then the laboratory examination becomes a bottleneck of the system, resulting in a increase in the average patients' LOS. To tackle these weaknesses, some goals have been established, namely: (i) dynamically change the patient's queue priority, based on his current waiting time; (ii) reduce the number of non eligible patients arriving at the ED; (iii) and reduce the lead time, i.e., the sum of waiting, transportation and examination times, need for laboratory examinations. The achievement of the first goal would permit to reduce the number of outliers, reducing the number of patients non eligible to the ED (second goal) would positively impact in the average waiting times, and making the laboratory work faster and more efficiently would lead to a reduction in the average LoS of the patients. To attain the previous goals, the following practical actions could be associated with them: (i) implementation of an alert system to support the dynamic priority rule; (ii) improving triage process to immediately dismiss non eligible white urgency code patients and (iii) to require laboratory exams to a certain group of patients during the triage process; (iv) and implementing a more efficient (and continuous) transportation system compared with the current one.

Based on the discussion above, we defined the following parameters to characterize our proposed scenarios: 1) patients with green or white urgency codes can go to the head of the queue for the first visit if their current waiting time exceeds $\tau_{g}$ and $\tau_{w}$ minutes, respectively; 2) patients with white urgency code are more likely to be non eligible to the $\mathrm{ED}$, one could assume that $e \%$ of them could be directed to more appropriated facilities; 3 ) $l \%$ of the laboratory exams could be required during the triage process; and 4) the lead time for laboratory exams are reduced in $r$ minutes.

Table 2. Parameters

\begin{tabular}{lr}
\hline Parameter & Chosen values \\
\hline$\tau_{g}$ & $60,90,120,210$ \\
$\tau_{w}$ & $120,180,210$ \\
$e$ & $5,10,15,20$ \\
$l$ & $10,15,20,50,60,75,100$ \\
$r$ & $10,15,20,25,30$ \\
\hline
\end{tabular}

Table 2 shows the parameters chosen. By combining them we establish our notion of scenario. Hence, let us define a scenario $S=\left(\tau_{g}, \tau_{w}, e, l, r\right)$ as a combination of parameters. For example, a scenario 
$S=(120,-, 5,-, 10)$ means that the priority for green coded patients changes if their waiting time exceeds 120 minutes; $5 \%$ of white urgency code patients are dismissed during the triage process; and the lead time for laboratory exams is 10 minutes shorter. The "-" sign state that the current configuration is not changed. Based on this observation, Table 3 presents the proposed scenarios. Scenarios with id $C$ are those proposing a new dynamic priority rule for the first visit queue. Scenarios of type $D$ and $E$ simulate an improvement in the triage process. The former implies in requiring a percentage of laboratory exams during the triage process, while the latter seeks reducing the number of non-eligible patients in the ED. Scenarios $G$ simulates the reduction in the laboratory lead-time. Finally, the last scenarios, labeled $C b$, are formed by combining scenarios $C, D, E$ and $G$.

Table 3. Proposed scenarios

\begin{tabular}{|c|c|c|c|c|c|c|c|c|c|c|c|c|c|c|c|c|c|c|c|}
\hline \multirow[b]{2}{*}{ Id } & \multicolumn{5}{|c|}{ Parameters } & \multirow[b]{2}{*}{ Id } & \multicolumn{6}{|c|}{ Parameters } & \multirow[b]{2}{*}{ Id } & \multicolumn{6}{|c|}{ Parameters } \\
\hline & $\tau_{g}$ & $\tau_{w}$ & $e$ & $l$ & $r$ & & & $\tau_{g}$ & $\tau_{w}$ & $e$ & $l$ & $r$ & & & $\tau_{g}$ & $\tau_{w}$ & $e$ & $l$ & $r$ \\
\hline C. 1 & ( 90, & 180 & - & - & - ) & D.1 & ( & - , & - & - & 50 & $-\quad)$ & E.1 & ( & - , & & 5 & - & - ) \\
\hline C. 2 & ( 210 & 210 & - & - & - ) & D. 2 & ( & - , & - & - & 60 & $-\quad)$ & & ( & - , & - & 10 & - & - ) \\
\hline C. 3 & ( 60, & 120 & - & - & - ) & D. 3 & ( & - , & - & - & 75 & - ) & Е.3 & ( & - , & - & 15 & - & - ) \\
\hline  & ( 90 , & - & - & - & - ) & . & ( & - , & - & - & 100 & - ) & .4 & ( & - & - & 20 & - & \\
\hline C. 5 & $(60$, & 180 & - , & - & - ) & D. 5 & ( & - , & - & - & 10 & $-\quad)$ & Cb.6 & ( & - & - & - & 10 & $15)$ \\
\hline C. 6 & ( 60 , & 210 &,- & - & - ) & D.6 & ( & - , & - & - & 15 & - ) & $\mathrm{Cb} .7$ & ( &,- & - & - & 20 & $15)$ \\
\hline C. 7 & $(120$ & - &,- & - & - ) & D.7 & ( & - & - & - & 20 & $-\quad)$ & $\mathrm{Cb} .8$ & ( & - & - & - & 10 & 20 \\
\hline G.1 & $(-$, & - &,- & - & $10)$ & Cb.1 & ( & 120 & - & 10 & 50 & - ) & Cb.9 & ( & - & - & - & 15 & $20)$ \\
\hline G. 2 & $(-$, & - & - & - & 15 ) & $\mathrm{Cb} .2$ & ( & 120 & - & 10 & 20 & $-\quad)$ & b. 10 & ( & - , & - & - & 20 & $20)$ \\
\hline G. 3 & $(-$, & - & - &,- 2 & $20)$ & $\mathrm{Cb} .3$ & ( & 120 & - & 10 & 50 & $30)$ & b. 11 & ( & - , & - & - & 10 & $30)$ \\
\hline G.4 & $(-$, & - , & - &,- 2 & 25 ) & $\mathrm{Cb} .4$ & ( & 120 & - & - & 50 & $-\quad)$ & 12 & ( & - , & - & - & 15 & $30)$ \\
\hline G. 5 & $(-$, & - & - &,- & 30 ) & $\mathrm{Cb} .5$ & ( & 90 & - & 10, & 50 & - ) & $\mathrm{Cb} .13$ & ( & 120 , & - & 15 & - & - ) \\
\hline & & & & & & & & & & & & & & & & - & - & 50 & 30 \\
\hline & & & & & & & & & & & & & Cb. 15 & & 120 & - & 15 & 50 & 30 \\
\hline
\end{tabular}

In addition to the scenarios shown in Table 3, other ones involving the addition of new medical resources as doctors and nurses, the change in the personnel work shift and priorities changes along the process have been proposed. However, after preliminary experiments, these scenarios have been classified as unpractical by the ED managers, thus not included in our analysis.

\subsection{Scenarios evaluation}

In this section, we present and evaluate our proposition by simulating the scenarios presented in Section 3.3. The DES model was implemented using the software AnyLogic 8.1.0 (https://www.anylogic.com/) for Microsoft Windows 10. We refer to Grigoryev (2015) for a generic tutorial on the AnyLogic software. The experiments were executed in a personal computer equipped with an Intel core i7-7500U $2.70 \mathrm{GHz}$ processor and $12 \mathrm{~GB}$ of RAM.

Each proposed scenario was simulated 10 times, and each run simulates 30 days of working in the ED. We compare the average results over these runs with those obtained by the 10 times 30 days simulations of the current ED setting on Table 1. As comparison reference values, we used the same KPI described previously in Section 3.2 (namely, LoS, the $\mathrm{WT}_{1 s t}$ and the number of outliers) to evaluate the scenarios in Table 3. In addition, for the simulated results we also show the average results for the WT for the last visit $\left(\mathrm{WT}_{\text {last }}\right)$. Tables 4 and 5 summarize our experiments. The values in boldface indicate a significant KPI change by the referenced simulated scenario when compared with the current simulated setting.

The results in Table 4 show that the scenarios of type $C$ have a direct impact in the outliers indicator. This is expected because the queue priorities for patients with a long WT changes when this value approximates the outliers thresholds values.

The results in Table 4 show that the scenarios of type $C$ have a direct impact in the outliers indicator. This is expected because the queue priorities for patients with a long WT changes when this value approximates the outliers thresholds values. Scenarios $D$ and $G$ act directly on the system bottleneck, i.e., the laboratory exams. It can be observed that the average $\operatorname{LoS}$ is reduced in most of the cases which is also an expected result. The scenarios of type $D$ consider that a percentage of laboratory exams are required during the triage process. Since this service is performed without requiring the patient presence, a saving time for waiting its results is attained, thus impacting positively in the LoS indicator. Scenarios $G$ work similarly because the laboratory results would be ready earlier than in the 
Table 4. Results obtained for scenarios of types $C, D, E$ and $G$

(a) Type $C$ - dynamic priorities

(b) Type $D$ - laboratory exams required during triage

\begin{tabular}{|c|c|c|c|c|c|c|c|c|c|c|c|c|c|}
\hline \multirow{2}{*}{ Scenario } & \multirow{2}{*}{ In } & \multirow{2}{*}{$W T_{1 s t}$} & \multirow{2}{*}{$W T_{\text {last }}$} & \multirow{2}{*}{ LoS } & \multicolumn{2}{|c|}{ Outliers (\%) } & \multirow{2}{*}{ Scenario } & \multirow{2}{*}{ In } & \multirow{2}{*}{$W T_{1 s t}$} & \multirow{2}{*}{$W T_{\text {last }}$} & \multirow{2}{*}{ LoS } & \multicolumn{2}{|c|}{ Outliers (\%) } \\
\hline & & & & & green & white & & & & & & green & white \\
\hline $\begin{array}{l}\text { Curr. setting } \\
\text { simulation }\end{array}$ & 238.23 & 70.52 & 54.94 & 208.60 & 3.89 & 25.48 & $\begin{array}{l}\text { Curr. setting } \\
\text { simulation }\end{array}$ & 238.23 & 70.52 & 54.94 & 208.60 & 3.89 & 25.48 \\
\hline C. 1 & 237.41 & 66.98 & 53.73 & 204.02 & 3.26 & 23.29 & D. 1 & 236.45 & 69.34 & 52.61 & 194.42 & 4.14 & 23.60 \\
\hline C. 2 & 237.41 & 69.38 & 51.15 & 204.07 & 4.31 & 8.75 & D. 2 & 237.65 & 69.06 & 52.78 & 191.92 & 3.80 & 24.31 \\
\hline C. 3 & 236.56 & 69.10 & 55.11 & 206.74 & 3.73 & 23.91 & D. 3 & 236.71 & 68.35 & 51.28 & 186.85 & 3.81 & 23.89 \\
\hline C. 4 & 237.43 & 72.54 & 43.40 & 199.67 & 0.00 & 29.32 & D. 4 & 237.55 & 70.93 & 53.84 & 185.97 & 3.91 & 25.70 \\
\hline C. 5 & 237.74 & 69.19 & 55.63 & 207.54 & 1.61 & 23.88 & D. 5 & 236.93 & 71.01 & 56.32 & 207.67 & 4.58 & 26.42 \\
\hline C. 6 & 237.30 & 69.28 & 55.33 & 207.00 & 1.23 & 23.70 & D. 6 & 237.35 & 69.79 & 54.12 & 202.90 & 4.37 & 25.63 \\
\hline C.7 & 237.34 & 69.64 & 53.76 & 205.97 & 0.24 & 23.98 & D.7 & 237.91 & 68.05 & 51.76 & 198.47 & 3.34 & 23.25 \\
\hline
\end{tabular}

(c) Type $E$ - non-eligible patients

\begin{tabular}{|c|c|c|c|c|c|c|c|c|c|c|c|c|c|}
\hline \multirow{2}{*}{ Scenario } & \multirow{2}{*}{ In } & \multirow{2}{*}{$W T_{1 s t}$} & \multirow{2}{*}{$W T_{\text {last }}$} & \multirow{2}{*}{ LoS } & \multicolumn{2}{|c|}{ Outliers (\%) } & \multirow{2}{*}{ Scenario } & \multirow{2}{*}{ In } & \multirow{2}{*}{$W T_{1 s t}$} & \multirow{2}{*}{$W T_{\text {last }}$} & \multirow{2}{*}{ LoS } & \multicolumn{2}{|c|}{ Outliers (\%) } \\
\hline & & & & & green & white & & & & & & green & white \\
\hline $\begin{array}{l}\text { Curr. setting } \\
\text { simulation }\end{array}$ & 238.23 & 70.52 & 54.94 & 208.60 & 3.89 & 25.48 & $\begin{array}{l}\text { Curr. setting } \\
\text { simulation }\end{array}$ & 238.23 & 70.52 & 54.94 & 208.60 & 3.89 & 25.48 \\
\hline E.1 & 235.74 & 67.67 & 53.93 & 203.98 & 3.52 & 24.27 & G.1 & 237.19 & 69.31 & 54.43 & 202.25 & 3.77 & 23.76 \\
\hline E. 2 & 237.58 & 62.91 & 47.23 & 195.00 & 2.81 & 20.45 & G.2 & 236.73 & 68.39 & 53.74 & 199.30 & 3.56 & 24.37 \\
\hline E. 3 & 231.47 & 59.93 & 45.19 & 190.78 & 2.77 & 20.75 & G. 3 & 236.44 & 68.26 & 53.34 & 197.83 & 3.63 & 23.22 \\
\hline \multirow[t]{2}{*}{ E. 4} & 228.00 & 53.88 & 40.25 & 182.05 & 1.97 & 16.73 & G.4 & 236.65 & 69.08 & 53.09 & 196.80 & 3.24 & 24.47 \\
\hline & & & & & & & G.5 & 237.65 & 69.37 & 54.03 & 195.42 & 4.12 & 24.62 \\
\hline
\end{tabular}

Table 5. Results for scenarios of type $\mathrm{Cb}$ - combination of scenarios

\begin{tabular}{|c|c|c|c|c|c|c|c|c|c|c|c|c|c|}
\hline \multirow{2}{*}{ Scenario } & \multirow{2}{*}{ In } & \multirow{2}{*}{$W T_{1 s t}$} & \multirow{2}{*}{$W T_{\text {last }}$} & \multirow{2}{*}{ LoS } & \multicolumn{2}{|c|}{ Outliers (\%) } & \multirow{2}{*}{ Scenario } & \multirow{2}{*}{ In } & \multirow{2}{*}{$W T_{1 s t}$} & \multirow{2}{*}{$W T_{\text {last }}$} & \multirow{2}{*}{ LoS } & \multicolumn{2}{|c|}{ Outliers (\%) } \\
\hline & & & & & green & white & & & & & & green & white \\
\hline $\begin{array}{l}\text { Curr. setting } \\
\text { simulation }\end{array}$ & 238.23 & 70.52 & 54.94 & 208.60 & 3.89 & 25.48 & $\begin{array}{l}\text { Curr. setting } \\
\text { simulation }\end{array}$ & 238.23 & 70.52 & 54.94 & 208.60 & 3.89 & 25.48 \\
\hline $\mathrm{Cb} .1$ & 234.79 & 65.38 & 51.49 & 191.07 & 0.04 & 22.27 & $\mathrm{Cb} .9$ & 237.68 & 69.94 & 52.41 & 195.33 & 4.02 & 24.99 \\
\hline $\mathrm{Cb} .2$ & 232.98 & 63.22 & 47.81 & 192.54 & 0.13 & 22.10 & Cb.10 & 236.62 & 69.20 & 52.68 & 194.46 & 4.23 & 23.79 \\
\hline $\mathrm{Cb} .3$ & 233.35 & 61.38 & 45.72 & 174.29 & 0.08 & 20.10 & Cb.11 & 236.45 & 69.78 & 51.58 & 192.45 & 3.95 & 24.23 \\
\hline $\mathrm{Cb} .4$ & 237.96 & 72.13 & 53.14 & 197.02 & 0.14 & 26.26 & $\mathrm{Cb} .12$ & 238.40 & 69.15 & 53.92 & 192.68 & 3.73 & 24.38 \\
\hline $\mathrm{Cb} .5$ & 237.28 & 75.92 & 45.11 & 194.79 & 0.02 & 32.06 & Cb.13 & 230.39 & 56.55 & 44.46 & 187.19 & 0.08 & 18.18 \\
\hline $\mathrm{Cb} .6$ & 235.70 & 67.66 & 53.50 & 196.74 & 3.82 & 23.02 & Cb.14 & 236.83 & 67.97 & 53.17 & 185.73 & 3.65 & 24.24 \\
\hline Cb.7 & 237.08 & 68.93 & 53.61 & 195.86 & 3.64 & 24.97 & Cb. 15 & 230.62 & 57.56 & 41.69 & 168.37 & 0.12 & 18.84 \\
\hline $\mathrm{Cb} .8$ & 236.35 & 69.50 & 52.04 & 195.50 & 4.49 & 24.28 & & & & & & & \\
\hline
\end{tabular}

current setting. Scenarios $E$ act directly in the quantity of patients arriving at the the ED, thus obtaining improving values for most of the KPI.

With regard to the results for the combined scenarios presented in Table 5, it can be noticed that all of them were able to improve the average LoS. This is mainly due to the fact that these scenarios combine the best characteristics from scenarios of type $C, D, E$ and $G$. In particular, scenarios $C b .3$ and $C b .15$ present a reduction in the LoS of $16 \%$ and $19 \%$, respectively.

\section{CONCLUDING REMARKS}

We designed a solution for a major Emergency Department (ED) of Italy, through the use of a simulation modeling tool integrated into a design process. Literature recognize the value of computer simulation as a tool that models different solutions by means of what-if scenarios, but at the same time recognizes that a major drawback of computer simulation is the low implementation ratio of the solutions identified with this tool. From the other side, design processes and techniques such as prototyping let involve different stakeholders in the design process and increase the chances of implementation success, but hardly involve rigorous numerical approaches. The case study presented did not allow for strong organizational changes as the involved ED was concerned about the impact of changes and they needed to develop confidence toward the future. 
In our ED redesigned effort we embedded the simulation technique in a design process. We used the simulation tool to create a virtual prototyping environment, to help the group to start a safe ideation and prototyping effort. Virtual prototyping injected into the organizational context increases the possibility of experimenting. It represented a cognitive low-risk environment where professionals could explore possible alternative solutions. Once the state of possible was brought into the group of health-care professionals, we developed organizational prototyping tools, by prototyping with them possible solutions that followed the paths identified by the computational simulation.

The proposed solutions were evaluated by comparing the obtained results with the ones of current setting through KPI. As the results seemed promising, the top management and head physicians gained confidence for a more grounded decision making effort and important choices of change management and investments have been made.

\section{REFERENCES}

Aringhieri, R., 2010. “An integrated DE and AB simulation model for ems management”. In: 2010 IEEE Workshop on Health Care Managemen. pp. 1-6.

Bate, P., Robert, G., 2006. "Experience-based design: from redesigning the system around the patient to co-designing services with the patient". BMJ Quality \& Safety, Vol. 15 No. 5, pp. 307-310.

Bate, P., Robert, G., 2007. "Toward more user-centric OD: Lessons from the field of experience-based design and a case study". The Journal of Applied Behavioral Science, Vol. 43 No. 1, pp. 41-66.

Bessant, J., Maher, L., 2009. "Developing radical service innovations in healthcare - the role of design methods". International Journal of Innovation Management, Vol. 13 No. 4, pp. 555-568.

Bevan, H., Robert, G., Bate, P., Maher, L., Wells, J., 2007. Using a design approach to assist large-scale organizational change: "10 high impact changes" to improve the national health service in england. The Journal of Applied Behavioral Science, Vol. 43 No. 1, pp. 135-152.

Brailsford, S. C., Lattimer, V. A., Tarnaras, P., Turnbull, J. C., Jan 2004. "Emergency and on-demand health care: modelling a large complex system". Journal of the Operational Research Society, Vol. 55 No. 1, pp. 34-42.

Brailsford, S. C., Carter, M. W., Jacobson, S. H., Dec 2017. "Five decades of healthcare simulation". In: 2017 Winter Simulation Conference (WSC). pp. 365-384.

Brown, T., 2008. "Design thinking. Harvard Business Review", Vol. 86 No. 6, pp. 84-92.

Cabrera, E., Taboada, M., Iglesias, M. L., Epelde, F., Luque, E., 2011. "Optimization of healthcare emergency departments by agent-based simulation”. Procedia Computer Science, Vol. 4, pp. 1880-1889.

Dosi, C., Ferrari, A., Vignoli, M., 2017. "Progettare soluzioni innovative con il design thinking in sanità: il caso del pronto soccorso di Reggio Emilia / Design innovative solutions with design thinking in the healthcare sector: the case of the emergency department in Reggio Emilia". Politiche sanitarie, Vol. 18 No. 4, pp. $166-175$.

Cottam, H., Leadbeater, C., 2004. Red paper 01 health: Co-creating services. Design Council.

Dosi C., Rosati F., Vignoli M., 2018. "Measuring Design Thinking mindset". 15th International Design Conference - DESIGN, Dubrovnik, Croatia.

Fone, D., Hollinghurst, S., Temple, M., Round, A., Lester, N., Weightman, A., Roberts, K., Coyle, E., Bevan, G., Palmer, S., 2003. "Systematic review of the use and value of computer simulation modelling in population health and health care delivery". Journal of Public Health Medicine, Vol. 25 No. 4, pp. 325-335.

Franchini, G., Dosi, C., Vignoli, M., 2017. "The coexistence of design thinking and stage and gate in the same organisational context-Challenges and need for integration". In DS 87-2 Proceedings of the 21st International Conference on Engineering Design (ICED 17) Vol 2: Design Processes, Design Organisation and Management, Vancouver, Canada, 21-25.08.2017.

Freire, K., Sangiorgi, D., 2010. Service design and healthcare innovation: from consumption, to co-production to co-creation. In: ServDes. 2010 - Conference on Service Design and Service Innovation. Linköping University Electronic Press, p. 239.

Grigoryev, I., 2015. AnyLogic 7 in Three Days. North Charleston CreateSpace Independent Publishing Platform, 2nd ed.

Gul, M., Guneri, A. F., 2015. "A comprehensive review of emergency department simulation applications for normal and disaster conditions". Computers \& Industrial Engineering, Vol. 83, pp. 327-344.

Günal, M. M., Pidd, M., 2010. "Discrete event simulation for performance modelling in health care: a review of the literature". Journal of Simulation, Vol. 4 No. 1, pp. 42-51.

Hempe, E.-M., Dickerson, T., P John Clarkson, A. H., 2012. "Health and social care services for people with complex needs: The importance of context in the design process". In: ServDes. 2010 - Conference on Service Design and Service Innovation. No. 60. Linköping University Electronic Press, pp. 145-146. 
Herzlinger, R. E., 2006. "Why innovation in health care is so hard". Harvard Business Review, Vol. 84 No. 5, pp. 58-66.

Hoot, N. R., Aronsky, D., 2008. "Systematic review of emergency department crowding: Causes, effects, and solutions". Annals of Emergency Medicine, Vol. 52 No. 2, pp. 126-136.

Hulshof, P. J. H., Kortbeek, N., Boucherie, R. J., Hans, E. W., Bakker, P. J. M., Dec 2012. “Taxonomic classification of planning decisions in health care: a structured review of the state of the art in OR/MS". Health Systems, Vol. 1 No. 2, pp. 129-175.

Iedema, R., Merrick, E., Piper, D., Britton, K., Gray, J., Verma, R., Manning, N., 2010. "Codesigning as a discursive practice in emergency health services: The architecture of deliberation". The Journal of Applied Behavioral Science, Vol. 46 No. 1, pp. 73-91.

Jelinek, M., Romme, A. G. L., Boland, R. J., 2008. "Introduction to the special issue: Organization studies as a science for design: Creating collaborative artifacts and research". Organization Studies, Vol. 29 No. 3, pp. $317-329$.

Liedtka, J., 2015. "Perspective: Linking design thinking with innovation outcomes through cognitive bias reduction". Journal of Product Innovation Management, Vol. 32 No. 6, pp. 925-938.

Madsen, P., Desai, V., Roberts, K., Wong, D., 2006. "Mitigating hazards through continuing design: The birth and evolution of a pediatric intensive care unit". Organization Science, Vol. 17 No. 2, pp. 239-248.

Marshall, A., Vasilakis, C., El-Darzi, E., 2005. "Length of stay-based patient flow models: Recent developments and future directions". Health Care Management Science, Vol. 8 No. 3, pp. 213-220.

Martin, R., 2010. Design thinking: achieving insights via the "knowledge funnel". Strategy \& Leadership, Vol. 38 No. 2, pp. 37-41.

McCreary, L., 2010. "Kaiser permanente's innovation on the front lines". Harvard Business Review, Vol. 88 No. 9, p. 92, pp. 94-97, 126.

Mohrman, S. A., 2007. "Having relevance and impact: The benefits of integrating the perspectives of design science and organizational development". The Journal of Applied Behavioral Science, Vol. 43 No. 1, pp. $12-22$.

Paul, S. A., Reddy, M. C., DeFlitch, C. J., 2010. "A systematic review of simulation studies investigating emergency department overcrowding”. Simulation, Vol. 86 No. 8-9, pp. 559-571.

Prada, G., 2008. "Exploring technological innovation in health systems: Is Canada measuring up?" Journal of Management \& Marketing in Healthcare, Vol. 1 No. 4, pp. 362-374.

Robinson, S., 1997. "Simulation model verification and validation: Increasing the users' confidence". In: Proceedings of the 29th Conference on Winter Simulation. WSC '97. IEEE Computer Society, Washington, DC, USA, pp. 53-59.

Romme, A. G. L., 2003. "Making a difference: Organization as design”. Organization Science, Vol. 14 No. 5, pp. 558-573.

Salmon, A., Rachuba, S., Briscoe, S., Pitt, M., 2018. "A structured literature review of simulation modelling applied to emergency departments: Current patterns and emerging trends". Operations Research for Health Care, Vol. 19, pp. 1-13.

Santibáñez, P., Chow, V. S., French, J., Puterman, M. L., Tyldesley, S., 2009. "Reducing patient wait times and improving resource utilization at british columbia cancer agency's ambulatory care unit through simulation". Health Care Management Science, Vol. 12 No. 4, pp. 392-407.

Schluse, M., Priggemeyer, M., Atorf, L., Rossmann, J., 2018. "Experimentable Digital Twins-Streamlining Simulation-Based Systems Engineering for Industry 4.0”. IEEE Transactions on Industrial Informatics, Vol. 14 No. 4, pp. 1722-1731.

Starnino, A., Dosi, C., Vignoli, M., 2016. "Designing the future, engineering reality: Prototyping in the emergency department". In: Service Design Geographies. Proceedings of the ServDes.2016 Conference. No. 125. Linköping University Electronic Press, pp. 574-579.

Trzeciak, S., Rivers, E. P., 2003. "Emergency department overcrowding in the united states: an emerging threat to patient safety and public health". Emergency Medicine Journal, Vol. 20 No. 5, pp. 402-405.

Vignoli, M., Macrí, D., Bertolotti, F., 2011. "Prototyping in organizational process engineering". In: ICED 11 18th International Conference on Engineering Design - Impacting Society Through Engineering Design, Vol. 3. pp. 233-244.

Weick, K. E., 2003. "Organizational design and the gehry experience”. Journal of Management Inquiry, Vol. 12 No. 1, pp. 93-97.

\section{ACKNOWLEDGMENTS}

This research was partially funded by the CNPq - Conselho Nacional de Desenvolvimento Científico e Tecnológico, Brazil, grant No. 234814/2014-4 and by University of Modena and Reggio Emilia, under grant FAR 2018 Analysis and optimization of health-care and pharmaceutical logistic processes. 